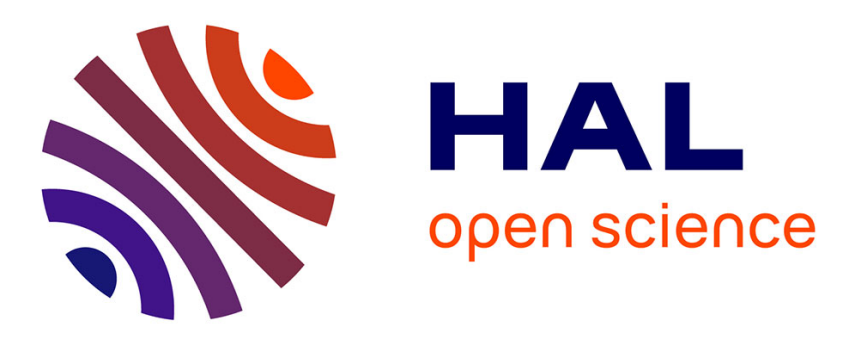

\title{
Judo rules: searching for a wind of changes
}

Michel Calmet, Emanuela Pierantozzi, Stanislaw Sterkowicz, Monica Yuri

Takito, Emerson Franchini

\section{To cite this version:}

Michel Calmet, Emanuela Pierantozzi, Stanislaw Sterkowicz, Monica Yuri Takito, Emerson Franchini. Judo rules: searching for a wind of changes. International Journal of Performance Analysis in Sport, 2018, 17 (6), pp.863-871. 10.1080/24748668.2017.1405612 . hal-01757648

\section{HAL Id: hal-01757648 \\ https://hal.science/hal-01757648}

Submitted on 3 Apr 2018

HAL is a multi-disciplinary open access archive for the deposit and dissemination of scientific research documents, whether they are published or not. The documents may come from teaching and research institutions in France or abroad, or from public or private research centers.
L'archive ouverte pluridisciplinaire HAL, est destinée au dépôt et à la diffusion de documents scientifiques de niveau recherche, publiés ou non, émanant des établissements d'enseignement et de recherche français ou étrangers, des laboratoires publics ou privés. 


\section{Judo rules: searching for a wind of changes}

Michel Calmet ${ }^{1 *}$, Emanuela Pierantozzi ${ }^{2}$, Stanislaw Sterkowicz ${ }^{3}$, Monica Yuri Takito ${ }^{4}$, Emerson Franchini ${ }^{5}$

1 -Université de Montpellier, Université d'Aix-Marseille, michel.calmet@umontpellier.fr

2 - University of Genoa, Italy. emanuela.pierantozzi@ unige.it

3 - Combat Sports Unit, Department of Theory of Sport and Kinesiology, University of Physical Education in Cracow, Poland stanislaw.sterkowicz@awf.krakow.pl

4 - Human Movement Pedagogy Department, Group, School of Physical Education and Sport, University of São Paulo, Brazil. mytakito@gmail.com

5 - Martial Arts and Combat Sports Research Group, School of Physical Education and Sport, University of São Paulo, Brazil. emersonfranchini@ hotmail.com 


\title{
Judo rules: searching for a wind of changes
}

\begin{abstract}
After 2016 the International Judo Federation changed rules to promote the "positive" judo. This study compared two World Championships editions before and after the rules changes: Astana-2015 and Budapest-2017. Data from matches disputed in Astana (765) and Budapest (768) were analyzed concerning: total match duration, frequency of scores and penalties, association between edition and extra-time, disqualifications and matches without penalties. Three-way ANOVA was used to compare sexes, weight categories and World-Championships-edition, with Fisher's Least Significant Difference (LSD) test as post-hoc. The associations between World-Championships-edition and matches finished in extra-time, disqualifications and matches without any score were tested via Chi-square. Results were: (a) no change in number of ippon when the same sex and weight category were considered across years; (b) number of waza-ari increased from Astana to Budapest; (c) number of penalties decreased from Astana to Budapest. Females in Budapest received less penalties than females in Astana and males in both competitions. Extralightweights received less penalties than lightweights upwards; heavyweights received more penalties than all other weight categories from middleweights downwards; (d) occurrence of extra-time and hansoku-make increased for females, males and all groups together; (e) males' matches were longer than females ones. Thus, the new rules partially achieved the goal proposed.
\end{abstract}

Keywords: performance analysis, competition (World Championship), technique, scores, combat sports. 


\section{1) Introduction}

Judo is grappling combat sport introduced as demonstration sport into the Olympic Games in 1964 for males and 1988 for females. Since Barcelona 1992 Olympic Games judo is a full sport for both males and females, disputed in seven weight categories for each sex (Brousse and Matsumoto, 1999). As the first originally Asian sport spread out worldwide, judo struggle to gain popularity, especially after the World War II when World Championships started to be disputed in 1956 (Carr, 1993). The main strategy to increase judo popularity was to make its rules easier for the general public to understand and to make them similar to other Western combat sports, such as wrestling and boxing, including weight categories, precise period of time, referee conduction of the combat, specific area of competition, colored uniforms (Brousse and Matsumoto, 1999; Carr, 1993). Since 2009 relevant rule changes have been introduced to make judo even more attractive for the general public. Among this rules changes, the creation of the World Ranking List introduction, elimination of the penalties and scores equivalence, prohibition of grab leg techniques, inclusion of grip breaks restrictions, weigh-in change for the day before competition, the use of video replay to decide controversial actions and scores, and the conduction of the match by only one referee inside the competition area were the main recent modifications (Franchini et al., 2013a, Franchini and Julio, 2015).

The main goal of these changes was to promote "positive" actions such as the constant search for ippon (i.e., the judo maximum score) instead of "negative" actions such as avoiding opponent's attacks (Boguszewski, 2011; Ito et al., 2013).

However, after these rule changes several authors reported that this main goal was not achieved (Balafoutas et al., 2013; Franchini et al., 2013b; Calmet et al., 2017). Briefly, Balafoutas et al. (2013) suggested that the excessive number of penalties would be disapproved by spectators and that the possibility of winning the match via penalties would create a conservative approach by athletes who would expose themselves less to the risk. Indeed, Franchini et al. (2013b) observed increased number of penalties and decreased number of waza-ari and yuko for males and females, while ippon scores increased only for males, with a collateral effect of increased number of disqualifications for this group, during the European Judo Championship disputed after the rule change incorporated after the London Olympic Games compared to the edition immediately before such changes. For the Rio Olympics, a set of new rules were introduced in 2013, but this did not work as expected as Calmet et al. (2017) reported that they resulted in no change in ippon and waza-ari scores, while decreasing the number of penalties in Rio 2016 compared to London 2012. The result seems not be approved by the International Judo Federation itself as new rules were set to start in 2017. The main modifications included the decrease in the time limit of males' matches for $4 \mathrm{~min}$ - a modification which was established for females in the previous Olympic period -, more rigorous criteria for awarding an ippon score, the exclusion of the yuko score (which in fact started to be considered a waza-ari), a higher period of tolerance for the inactivity before a penalty would be given - although the disqualification would be achieved with three penalties and not four as before -, and the exclusion of win possibility via penalties in the regular period, i.e., except by disqualification of his/her opponent the other athlete would not be considered if he/she had only an advantage generated by his/her opponent being penalized (IJF, 2017). Thus, a win in the regular 4- 
min period would be possible only via scores or opponent disqualification, imposing a demand for score to win the match more than relying on opponent's being penalized (IJF, 2017).

Considering that the new rules were established, the main goal of this paper was to compare the scores, penalties and match's time duration between two World Championships, one before and another after the rule changes, considering each sex and the seven weight categories. The main hypotheses of the present study were that the new rules would result in (a) no change concerning number of ippon would not change, (b) in an increase in the number of waza-ari (as by the new rules two waza-ari are not converted into an ippon and more than two waza-ari are possible for each athlete), and (c) in a decrease in the number of penalties (as penalties do not decide the match in regular time).

\section{2) Methods}

\subsection{Data sample}

The results published on the International Judo Federation official website for judo statistics (www.judobase.org) were retrieved in September $10^{\text {th }} 2017$. For example, after searching for the 2017 World Championship, the following link allows to find the general data of Budapest World Championship:

https://judobase.ijf.org/\#/competition/profile/1463/contests.

By selecting each weight category, it is possible to retrieve all the data for that championship. Total match duration, total number of scores and penalties per match were used to compare males and females, concerning weight categories, (Extralightweight: up to $48 \mathrm{~kg}$ for females, and up to $60 \mathrm{~kg}$ for males; Half-lightweight: more than $48 \mathrm{~kg}$ and up to $52 \mathrm{~kg}$ for females, and more than $60 \mathrm{~kg}$ and up to $66 \mathrm{~kg}$ for males; Lightweight: more than $52 \mathrm{~kg}$ and up to $57 \mathrm{~kg}$ for females, and more than $66 \mathrm{~kg}$ and up to $73 \mathrm{~kg}$ for males; Half-middleweight: more than $57 \mathrm{~kg}$ and up to $63 \mathrm{~kg}$ for females, and more than $73 \mathrm{~kg}$ and up to $81 \mathrm{~kg}$ for males; Middleweight: more than $63 \mathrm{~kg}$ and up to $70 \mathrm{~kg}$ for females, and more than $81 \mathrm{~kg}$ and up to $90 \mathrm{~kg}$ for males; Half-heavyweight: more than $70 \mathrm{~kg}$ and up to $78 \mathrm{~kg}$ for females, and more than $90 \mathrm{~kg}$ and up to $100 \mathrm{~kg}$ for males; Heavyweight: more than $78 \mathrm{~kg}$ for females, and more than $100 \mathrm{~kg}$ for males), and World Championship's edition (Astana 2015 and Budapest 2017). As yuko was removed after the new rule changes, but the criteria set for yuko was now considered as waza-ari, all yuko scores from 2015 were considered as waza-ari for effect of comparison with the new rules. For penalties, no direct substitution was possible as the maximal number of penalties changed from four to three, although more time was allowed without attacks before a penalty was given in the new rules. Thus, we compared the total number of penalties and, alternatively, compared the proportion of disqualifications were also considered.

A total of 765 matches disputed in Astana 2015 and 768 matches disputed in Budapest 2017 was used in the present study. Scores and penalties were quantified per match per athlete as each athlete can have different scores and penalties, while total duration was considered only per match as the same duration applies to both athletes fighting a given match. 


\subsection{Ethics}

Morley and Thomas (2005) affirm that there are no ethical issues in analyzing or interpreting these data from open access websites, since all results were obtained in secondary form and not generated by experimentation. Additionally, athletes' personal identification is not reported as only final results were considered.

\subsection{Statistics}

Data are presented as mean and standard deviation and $95 \%$ confidence interval. Time, scores and penalties were compared across weight categories, World Championship's edition and sexes using three-way analysis of variance. Fisher's Least Significant Difference (LSD) test was used as post hoc. Partial eta squared $\left(\eta^{2}\right)$ was used as effect size. The associations between World Championship's edition and percentage of matches without any score, with disqualification and with extra-time were tested via Chi-square and Cramer's - V (PHI) effect size was used. Significance level was set at 5\%. Data were analyzed using the Statistica for Windows software (version 10, StatSoft Inc., Tulsa, USA).

\section{3) Results}

Number of ippon scored per athlete per match for each sex, weight category and World Championship edition is presented on Table 1.

No effects of sex $\left(\mathrm{F}_{1,3038}=0.66 ; \mathrm{P}=0.419 ; \eta^{2}<0.001\right.$ [small effect] $)$, weight category $\left(\mathrm{F}_{6,3038}=1.37 ; \mathrm{P}=0.225 ; \eta^{2}=0.003\right.$ [small effect] $)$ or World Championship edition $\left(\mathrm{F}_{1,3038}=0.04 ; \mathrm{P}=0.836 ; \eta^{2}<0.001\right.$ [small effect] $)$ or interaction between sex and weight category $\left(\mathrm{F}_{6,3038}=0.10 ; \mathrm{P}=0.997 ; \eta^{2}<0.001\right.$ [small effect] $)$, weight category and World Championship edition $\left(\mathrm{F}_{6,3038}=0.43 ; \mathrm{P}=0.858 ; \eta^{2}=0.001\right.$ [small effect $])$, sex, weight category and World Championship edition $\left(\mathrm{F}_{6,3038}=0.39 ; \mathrm{P}=\right.$ 0.884; $\eta^{2}=0.001$ [small effect]) were found. However, a sex and World Championship edition interaction was observed $\left(\mathrm{F}_{1,3038}=5.95 ; \mathrm{P}=0.015 ; \eta^{2}=0.002\right.$ [small effect]), with lower number of ippon for females in Astana compared to males in Astana $(\mathrm{P}=$ $0.021)$. 
Table 1: Number of ippon scored per athlete per match in different weight categories and sexes during Astana 2015 and Budapest 2017 World Championships.

Female (n/athlete/match) $\quad$ Males (n/athlete/match)

\begin{tabular}{lcccc} 
& Astana $2015^{\mathrm{a}}$ & Budapest 2017 & Astana 2015 & Budapest 2017 \\
\hline 48 or $60 \mathrm{~kg}$ & $0.28 \pm 0.45(0.18 ; 0.37)$ & $0.28 \pm 0.45(0.18 ; 0.38)$ & $0.25 \pm 0.44(0.18 ; 0.33)$ & $0.29 \pm 0.46(0.21 ; 0.37)$ \\
52 or $66 \mathrm{~kg}$ & $0.25 \pm 0.44(0.16 ; 0.34)$ & $0.34 \pm 0.47(0.25 ; 0.43)$ & $0.33 \pm 0.47(0.24 ; 0.41)$ & $0.28 \pm 0.45(0.21 ; 0.36)$ \\
57 or $73 \mathrm{~kg}$ & $0.23 \pm 0.42(0.16 ; 0.31)$ & $0.29 \pm 0.46(0.21 ; 0.38)$ & $0.30 \pm 0.46(0.23 ; 0.37)$ & $0.28 \pm 0.45(0.20 ; 0.35)$ \\
63 or $81 \mathrm{~kg}$ & $0.24 \pm 0.43(0.15 ; 0.32)$ & $0.28 \pm 0.45(0.19 ; 0.37)$ & $0.31 \pm 0.46(0.24 ; 0.38)$ & $0.28 \pm 0.45(0.20 ; 0.35)$ \\
70 or $90 \mathrm{~kg}$ & $0.27 \pm 0.44(0.21 ; 0.32)$ & $0.26 \pm 0.44(0.17 ; 0.35)$ & $0.32 \pm 0.47(0.24 ; 0.40)$ & $0.21 \pm 0.41(0.14 ; 0.28)$ \\
78 or $100 \mathrm{~kg}$ & $0.26 \pm 0.44(0.16 ; 0.37)$ & $0.31 \pm 0.47(0.20 ; 0.42)$ & $0.33 \pm 0.47(0.24 ; 0.41)$ & $0.28 \pm 0.45(0.19 ; 0.36)$ \\
+78 or $+100 \mathrm{~kg}$ & $0.30 \pm 0.46(0.19 ; 0.40)$ & $0.38 \pm 0.49(0.27 ; 0.50)$ & $0.38 \pm 0.49(0.28 ; 0.48)$ & $0.33 \pm 0.47(0.24 ; 0.43)$
\end{tabular}

Data are mean and standard deviation and 95\% confidence interval; a = sex and World Championship interaction effect, different from males in Astana ( $\mathrm{p}<0.05)$ 
Number of waza-ari scored per athlete per match for each sex, weight category and World Championship edition is presented on Table 2.

No effects of $\operatorname{sex}\left(\mathrm{F}_{1,3038}=1.77 ; \mathrm{P}=0.184 ; \eta^{2}=0.001\right.$ [small effect]), weight category $\left(\mathrm{F}_{6,3038}=1.56 ; \mathrm{P}=0.156 ; \eta^{2}=0.003\right.$ [small effect]) or interaction effects (sex and weight category: $\mathrm{F}_{6,3038}=0.50 ; \mathrm{P}=0.810 ; \eta^{2}=0.001$ [small effect]; weight category and World Championship edition: $\mathrm{F}_{6,3038}=0.32 ; \mathrm{P}=0.925 ; \eta^{2}=0.001$ [small effect]; sex and World Championship: $\mathrm{F}_{1,3038}=0.03 ; \mathrm{P}=0.853 ; \eta^{2}<0.001$ [small effect]; or sex, weight category and World Championship edition: $\mathrm{F}_{6,3038}=0.77 ; \mathrm{P}=$ 0.594; $\eta^{2}=0.002$ [small effect]) were found. However, an effect of World Championship edition $\left(\mathrm{F}_{1,3038}=32.30 ; \mathrm{P}<0.001 ; \eta^{2}=0.011\right.$ [small effect]) was observed, with lower number of waza-ari in Astana compared to Budapest ( $\mathrm{p}<0.001$ ). 
Table 2: Number of waza-ari scored per athlete per match in different weight categories and sexes during Astana 2015 and Budapest 2017 World Championships.

Female (n/athlete/match) Males (n/athlete/match)

\begin{tabular}{lcccc} 
& Astana $2015^{\mathrm{a}}$ & Budapest 2017 & Astana 2015 & Budapest 2017 \\
\hline 48 or $60 \mathrm{~kg}$ & $0.28 \pm 0.52(0.17 ; 0.39)$ & $0.41 \pm 0.64(0.26 ; 0.55)$ & $0.31 \pm 0.65(0.20 ; 0.42)$ & $0.41 \pm 0.70(0.29 ; 0.53)$ \\
52 or $66 \mathrm{~kg}$ & $0.27 \pm 0.44(0.16 ; 0.38)$ & $0.33 \pm 0.47(0.25 ; 0.43)$ & $0.28 \pm 0.52(0.19 ; 0.37)$ & $0.41 \pm 0.76(0.29 ; 0.54)$ \\
57 or $73 \mathrm{~kg}$ & $0.29 \pm 0.59(0.19 ; 0.40)$ & $0.34 \pm 0.57(0.23 ; 0.45)$ & $0.31 \pm 0.61(0.22 ; 0.41)$ & $0.52 \pm 0.76(0.40 ; 0.64)$ \\
63 or $81 \mathrm{~kg}$ & $0.28 \pm 0.51(0.18 ; 0.38)$ & $0.36 \pm 0.56(0.25 ; 0.47)$ & $0.28 \pm 0.55(0.20 ; 0.37)$ & $0.43 \pm 0.66(0.32 ; 0.54)$ \\
70 or $90 \mathrm{~kg}$ & $0.32 \pm 0.57(0.25 ; 0.38)$ & $0.58 \pm 0.76(0.42 ; 0.73)$ & $0.34 \pm 0.57(0.25 ; 0.44)$ & $0.48 \pm 0.70(0.37 ; 0.59)$ \\
78 or $100 \mathrm{~kg}$ & $0.25 \pm 0.50(0.14 ; 0.36)$ & $0.40 \pm 0.60(0.25 ; 0.54)$ & $0.26 \pm 0.50(0.17 ; 0.35)$ & $0.42 \pm 0.67(0.30 ; 0.55)$ \\
+78 or $+100 \mathrm{~kg}$ & $0.22 \pm 0.53(0.10 ; 0.34)$ & $0.40 \pm 0.72(0.23 ; 0.57)$ & $0.31 \pm 0.59(0.19 ; 0.43)$ & $0.38 \pm 0.65(0.24 ; 0.51)$
\end{tabular}

Data are mean and standard deviation and 95\% confidence interval; $\mathrm{a}=$ main effect of World Championship edition, different from Budapest ( $\mathrm{p}<0.001$ ) 
Number of penalties per athlete per match for each sex, weight category and World Championship edition is presented on Table 3.

For penalties, there were effects of $\operatorname{sex}\left(\mathrm{F}_{1,3010}=29.56 ; \mathrm{P}<0.001 ; \eta^{2}=0.010\right.$ [small effect]), weight category $\left(\mathrm{F}_{6,3010}=6.21 ; \mathrm{P}<0.001 ; \eta^{2}=0.012\right.$ [small effect] $)$ and World Championship edition $\left(\mathrm{F}_{1,3010}=32.66 ; \mathrm{P}<0.001 ; \eta^{2}=0.011\right.$ [small effect]). There was also a sex and competition interaction effect $\left(\mathrm{F}_{1,3010}=4.02 ; \mathrm{P}=0.043 ; \eta^{2}=\right.$ 0.001 [small effect]). The post hoc revealed a decrease in the number of penalties from Astana to Budapest ( $\mathrm{p}<0.001$ ), and lower number of penalties for females compared to males $(\mathrm{p}<0.001)$. Concerning weight categories, the extra-lightweights received less penalties compared to lightweights $(\mathrm{p}=0.011)$, middleweights, half-heavyweights and heavy weights ( $p<0.001$ for the three comparisons), while lightweights received lower number of penalties than half-heavyweights $(\mathrm{p}=0.018)$, and heavyweights received more penalties than all weight categories from middleweights downwards $(p<0.001$ for all four comparisons). Concerning the interaction effect, the post hoc revealed that females in Budapest received less penalties than females in Astana $(p=0.017)$, males in Astana $(\mathrm{p}<0.001)$ and Budapest $(\mathrm{p}=0.018)$, and complimentarily males in Astana received more penalties than females in Astana and males in Budapest $(p<0.001$ for both comparisons).

However, no effects of interaction were found for sex and weight category $\left(\mathrm{F}_{6,3010}=1.21 ; \mathrm{P}=0.283 ; \eta^{2}=0.003\right.$ [small effect] $)$, weight category and World Championship edition $\left(\mathrm{F}_{6,3010}=1.22 ; \mathrm{P}=0.292 ; \eta^{2}=0.002\right.$ [small effect] $)$ and sex, weight category and World Championship edition $\left(\mathrm{F}_{6,3010}=1.20 ; \mathrm{P}=0.304 ; \eta^{2}=0.002\right.$ [small effect]).

Table 4 presents the number and percentage of matches that needed an extratime, that resulted in disqualification of one athlete by sum of shido (4 or 3 depending on the year), that resulted in direct disqualification of one athlete and that finished without any athlete being punished for males and females in each of the World Championships. 
Table 3: Number of penalties per athlete per match in different weight categories and sexes during Astana 2015 and Budapest 2017 World Championships.

Female (n/athlete/match) ${ }^{\mathrm{a}} \quad$ Males (n/athlete/match)

\begin{tabular}{lcccc} 
& Astana $2015^{\mathrm{b}, \mathrm{f}}$ & Budapest 2017 & Astana $2015^{\mathrm{b}, \mathrm{g}}$ & Budapest 2017 \\
\hline 48 or $60 \mathrm{~kg}^{\mathrm{c}}$ & $0.51 \pm 0.70(0.36 ; 0.65)$ & $0.59 \pm 0.77(0.41 ; 0.76)$ & $1.05 \pm 1.05(0.86 ; 1.23)$ & $0.81 \pm 0.92(0.65 ; 0.97)$ \\
52 or $66 \mathrm{~kg}$ & $0.70 \pm 0.88(0.52 ; 0.88)$ & $0.87 \pm 0.92(0.70 ; 1.04)$ & $1.25 \pm 1.13(1.05 ; 1.44)$ & $0.90 \pm 0.91(0.75 ; 1.04)$ \\
57 or $73 \mathrm{~kg}^{\mathrm{d}}$ & $0.94 \pm 0.96(0.76 ; 1.11)$ & $0.70 \pm 0.82(0.55 ; 0.86)$ & $1.09 \pm 1.15(0.91 ; 1.27)$ & $0.82 \pm 0.83(0.69 ; 0.95)$ \\
63 or $81 \mathrm{~kg}$ & $0.91 \pm 0.93(0.73 ; 1.09)$ & $0.67 \pm 0.84(0.51 ; 0.83)$ & $1.23 \pm 1.07(1.06 ; 1.40)$ & $0.85 \pm 0.90(0.70 ; 1.00)$ \\
70 or $90 \mathrm{~kg}$ & $1.12 \pm 1.06(0.89 ; 1.34)$ & $0.87 \pm 0.95(0.67 ; 1.06)$ & $1.29 \pm 1.17(1.09 ; 1.49)$ & $0.92 \pm 0.93(0.77 ; 1.07)$ \\
78 or $100 \mathrm{~kg}$ & $1.01 \pm 1.16(0.75 ; 1.28)$ & $0.81 \pm 0.87(0.60 ; 1.01)$ & $1.11 \pm 1.07(0.92 ; 1.31)$ & $1.06 \pm 0.93(0.89 ; 1.23)$ \\
+78 or $+100 \mathrm{~kg})$ & $1.24 \pm 1.12(0.99 ; 1.50)$ & $0.97 \pm 1.08(0.71 ; 1.23)$ & $1.34 \pm 1.32(1.07 ; 1.62)$ & $1.00 \pm 0.98(0.80 ; 1.20)$
\end{tabular}

Data are mean and standard deviation and 95\% confidence interval; $a=$ main effect of sex, different from males ( $p<0.001)$; $b=$ main effect of World Championship edition, different from Budapest ( $\mathrm{p}<0.001)$; $\mathrm{c}=$ weight category effect, different from 70 or $90 \mathrm{~kg}, 78$ or $100 \mathrm{~kg}$ and +78 or $+100 \mathrm{~kg}(\mathrm{p}<0.001)$; $\mathrm{d}=$ weight category effect, different from 78 or $100 \mathrm{~kg}(\mathrm{p}<0.05)$; e = weight category effect, different from 63 or $81 \mathrm{~kg}, 57 \mathrm{or} 73 \mathrm{~kg}, 52 \mathrm{or} 66 \mathrm{~kg}$ and 48 or $60 \mathrm{~kg}$ (p < 0.001$)$; $=$ interaction effect, different from females in Budapest ( $\mathrm{p}<0.05)$, and males in Astana and Budapest $(\mathrm{p}<0.05)$; $\mathrm{g}=$ interaction effect, different from females in Astana and males in Budapest $(\mathrm{p}<0.001)$. 
Table 4: Number and percentage of matches (in parenthesis) that needed an extra-time, resulted in disqualification of one athlete by sum of shido (4 or 3 depending on the year), resulted in direct disqualification of one athlete or finished without any athlete being punished for males and females in each of the World Championships.

\begin{tabular}{|c|c|c|c|c|c|c|}
\hline & \multicolumn{2}{|c|}{ Females } & \multicolumn{2}{|c|}{ Males } & \multicolumn{2}{|c|}{ All } \\
\hline & 2015 & 2017 & 2015 & 2017 & 2015 & 2017 \\
\hline Extra-time (\%) & $26(8.18)^{*}$ & $70(22.58)$ & $10(2.24) *$ & $115(25.11)$ & $36(4.71)^{*}$ & $185(24.09)$ \\
\hline Hansoku-make by sum of shido (\%) & $7(2.20)^{*}$ & $34(10.97)$ & $29(6.49)^{*}$ & $51(11.14)$ & $36(4.71)^{*}$ & $85(11.07)$ \\
\hline Direct hansoku-make (\%) & $6(1.89)$ & $5(1.61)$ & $9(2.01)$ & $8(1.75)$ & $15(1.96)$ & $13(1.69)$ \\
\hline No penalty (\%) & $77(24.21)$ & $88(28.38)$ & 79 (17.67) & $91(19.87)$ & $156(20.39)$ & $179(23.31)$ \\
\hline
\end{tabular}


There was an association between World Championships edition and extra-time occurrences for females $\left(\chi^{2}=25.15, \mathrm{P}<0.001\right.$, PHI $=0.20$ [small effect]), males $\left(\chi^{2}=\right.$ 99.41, $\mathrm{P}<0.001, \mathrm{PHI}=0.33$ [medium effect] $)$ and all together $\left(\chi^{2}=116.70, \mathrm{P}<0.001\right.$, PHI $=0.28$ [small effect]). There was also an association between World Championships edition and hansoku-make derived from shido occurrences for females $\left(\chi^{2}=19.77, \mathrm{P}<0.001, \mathrm{PHI}=0.18\right.$ [small effect] $)$, males $\left(\chi^{2}=6.06, \mathrm{P}=0.014, \mathrm{PHI}=\right.$ 0.08 [very small effect] $)$ and all together $\left(\chi^{2}=21.16, \mathrm{P}<0.001, \mathrm{PHI}=0.12\right.$ [small effect]). However, there was no association between World Championships edition and direct hansoku-make (females: $\chi^{2}=0.07, \mathrm{P}=0.794, \mathrm{PHI}=0.01$ [very small effect]; males: $\chi^{2}=0.09, \mathrm{P}=0.768, \mathrm{PHI}=0.01$ [very small effect]; all together: $\chi^{2}=0.16$ [small effect]), $\mathrm{P}=0.694, \mathrm{PHI}=0.01$ [very small effect]) or number of matches without any penalty (females: $\chi^{2}=1.41, \mathrm{P}=0.235$, PHI $=0.05$ [very small effect]; males: $\chi^{2}=$ $0.72, \mathrm{P}=0.0 .398, \mathrm{PHI}=0.03$ [very small effect]; all together: $\chi^{2}=1.91, \mathrm{P}=0.170, \mathrm{PHI}$ $=0.04$ [very small effect]).

Figure 1 presents the match time for female (Panel A) and males (Panel B) from

different weight categories competing in Astana 2015 and Budapest 2017 Judo World Championships.

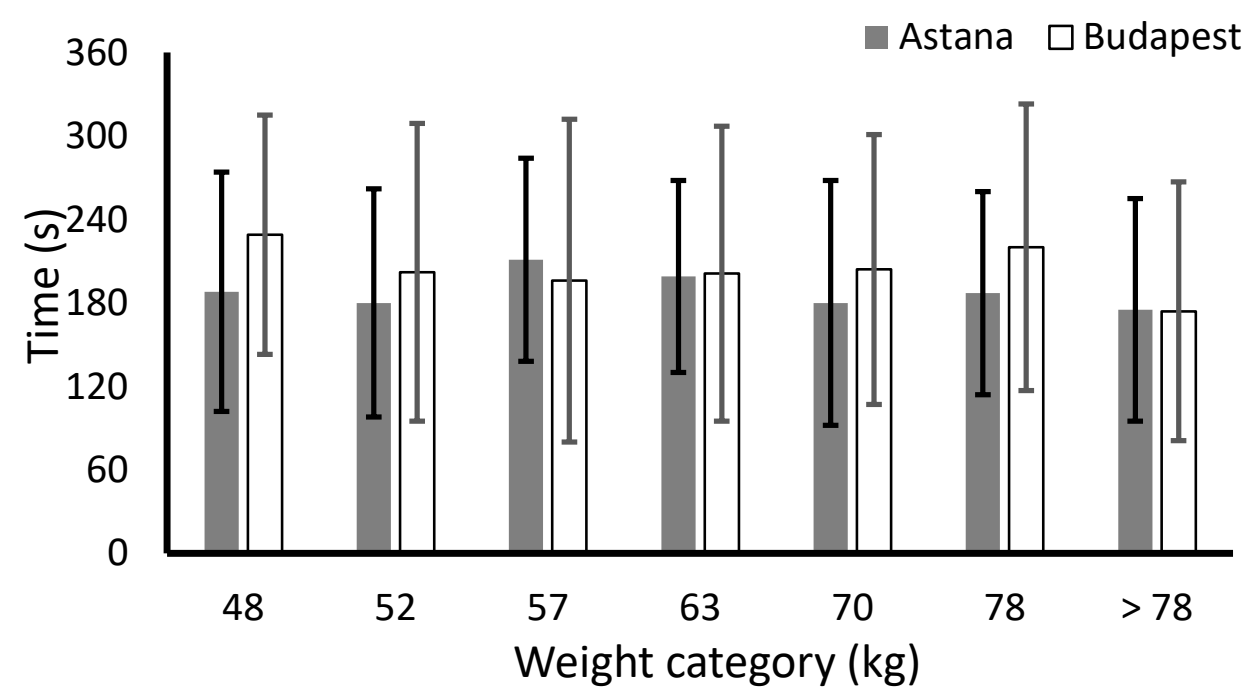

Panel A 


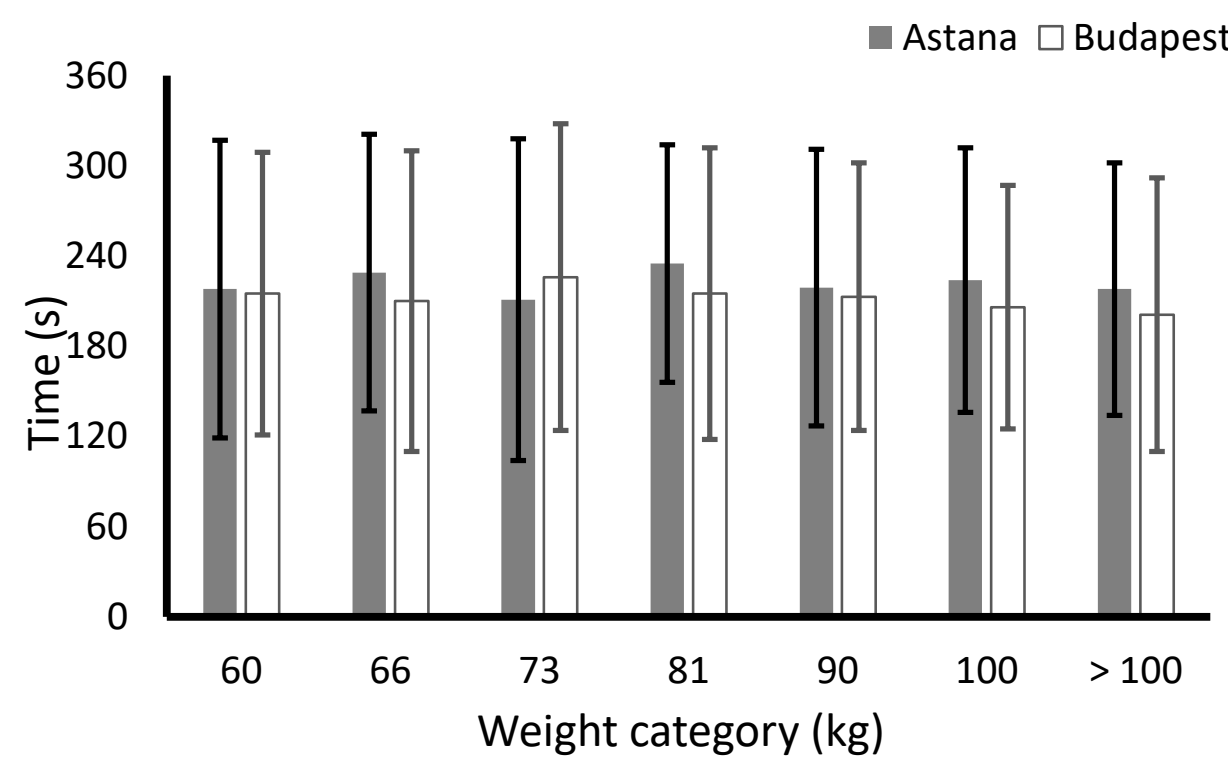

Panel B

Data are mean and standard deviation; for details concerning differences, see text.

Figure 1: Match time for female (Panel A) and males (Panel B) from different weight categories competing in Astana 2015 and Budapest 2017 Judo World Championships.

For match time a significant effect of sex was found $\left(\mathrm{F}_{1,1505}=18.56 ; \mathrm{P}<0.001\right.$; $\eta^{2}=0.012$ [small effect]), with lower values for females compared to males $(\mathrm{p}<0.001)$. There was also a sex and competition interaction effect $\left(\mathrm{F}_{1,1505}=6.43 ; \mathrm{P}=0.011 ; \eta^{2}=\right.$ 0.004 [small effect]), with males' matches in Astana lasting longer than females in Astana $(\mathrm{p}<0.001)$ and in Budapest $(\mathrm{p}=0.007)$ and males Budapest lasting longer than females in Astana $(\mathrm{p}<0.001)$. No significant effects of weight category $\left(\mathrm{F}_{6,1505}=1.34\right.$; $\mathrm{P}=0.235 ; \eta^{2}=0.005$ [small effect] $)$ or competition $\left(\mathrm{F}_{1,1505}=0.43 ; \mathrm{P}=0.511 ; \eta^{2}=\right.$ 0.003 [small effect]) were observed. Additionally, no interaction effects of sex and weight category $\left(\mathrm{F}_{1,1505}=0.67 ; \mathrm{P}=0.672 ; \eta^{2}=0.003\right.$ [small effect]), weight category and competition $\left(\mathrm{F}_{6,1505}=0.61 ; \mathrm{P}=0.724 ; \eta^{2}=0.002\right.$ [small effect] $)$ or sex, weight category and competition $\left(\mathrm{F}_{6,1505}=1.28 ; \mathrm{P}=0.263 ; \eta^{2}=0.005\right.$ [small effect] $)$ were detected. 


\section{4) Discussion}

The main findings of the present study were that: (a) there was no change and a small effect size was observed in ippon when the same sex and weight category were considered across years; (b) even summing up yuko and waza-ari scored in Astana, considering all as waza-ari, the result was lower than the number of waza-ari scored in Budapest, although the effect size calculation indicated a small effect; (c) the number of penalties decreased from Astana to Budapest. Additionally, females received less penalty than males, and specifically females in Budapest received less penalties than females in Astana and males in both World Championship editions. Furthermore, the extra-lightweight category (48 and $60 \mathrm{~kg}$ for females and males, respectively) received less penalties than lightweights upwards and heavyweights received more penalties than all other weight categories from middleweights downwards. However, for all these differences the effect size was considered small; (d) the occurrence of extra-time and hansoku-make increased for females, males and all groups together; (e) females matches were shorter than males ones, although small effect size was observed. Specifically, males' matches in Astana were longer than females' matches in both competitions and males' matches in Budapest were also longer than females' matches in Astana.

These results are different from investigations analyzing other rules changes in judo (Calmet et al., 2017; Franchini et al., 2013a) that demonstrated that the modifications had no positive or even a detrimental effect. After the London Olympic Games, the IJF changed the rules and Franchini et al. (2013a) demonstrated that the proposed modifications resulted in an increase in the number of penalties, a decrease in the number of waza-ari and yuko scores for both males and females, while the number of ippon and hansoku-make increased only for males. While comparing the London and Rio Olympic Games, Calmet et al. (2017) reported that the rules changes did not modify the prevalence of ippon and waza-ari scores, but decreased the number of yuko scores and increased the number of penalties. Conversely, the recent rules changes investigated in the present study increased the number of waza-ari scores and decreased the number of penalties, while keeping stable the number of ippon scores. Considering the suggestion from Balafoutas et al. (2013) that scores are preferred by spectators than penalties, these changes seem to have achieved the initial goal of increasing combativeness and promote what has been called positive judo. This can be related to the fact that winning a match by making the opponent being penalized can only be possible if he/she is disqualified or in the extra-time. Prior to these rules change it was reported that defeated athletes received shido three times more often than winners (Escobar-Molina et al., 2014), suggesting that improving the tactics to generate a penalty to the opponent was an important way to win the match. In fact, part of this process - fighting to make the opponent be penalized - is still present as our results indicate that the number of hansoku-make increased for females, males and all groups 
together. However, it seems that most of the athletes are using more positive strategies to win, as the total number of penalties decreased and the number of waza-ari increased. Indeed, female judo athletes seem to have been more positively affected by the rules changes as they received less penalties than males, and specifically females in Budapest received less penalties than females in Astana and males in both World Championship editions. The higher combativeness of female athletes compared to males was also observed in a previous study comparing the last two Olympic Games edition concerning scores and penalties (Franchini et al., 2013a).

Concerning weight categories, the lower number of penalties for the lightest athletes and higher number for the heaviest ones indicate that the combativeness decreases as the athletes' weight category increases, which may be related mainly to the physical fitness of these athletes, are it has been described that relative aerobic power, relative anaerobic power and capacity and relative maximal strength and muscle power are lower in heavier athletes compared to lightest ones (Franchini et al., 2011; Franchini et al., 2013b).

The fact that ippon score did not change can be explained by the fact that now two waza-ari scores do not sum up to generate an ippon, as in the previous rules, some competitors scored more than two waza-ari (13 competitors obtained 3 waza-ari, 2 obtained 2 waza-ari and 1 obtained 5 waza-ari scores; data not shown) and by the fact that more strict points must be present to generate an ippon from a throwing technique, especially the need for a flat and direct contact of the back with ground.

Another important aspect that changed after these rules modifications was the higher incidence of extra-time, although the total match duration did not change significantly. This result is a combination of the decrease in total males' match duration from 5-min to 4-min and to the fact that most of the matches tied in the regular time finished in the first minute of the extra-time.

This new scenario can have positive impact in the audience, because most matches are decided by scores and not by penalties as before, and the maintenance of total match duration combined to the excitement derived from the eminence of a determinant score (the so called golden-score) that can end the match certainly can increase the public interest, while maintaining the judo essential characteristics. However, the effects of these rules changes on public interest remain to be investigated.

The authors declare that there is no conflict of interest.

\section{5) References}


Balafoutas, L. Lindner, F. Sutter, M. (2013), Sabotage in tournaments: evidence from a natural experiment, Kylos, 65, 425-441

Boguszewski, D. (2011), Relationships between the rules and the way of struggle applied by top world male judoists, Archives of Budo, 7, 27-32

Brousse, M. and Matsumoto, D. (1999), Judo - a sport and way of life, International Judo Federation.

Calmet, M. Pierantozzi, E. Sterkowicz, S. Challis, B., Franchini, E. (2017), Rule change and Olympic judo scores, penalties and match duration, International Journal of Performance Analysis in Sport, e-ahead of print

Carr, K.G, (1993), Making way: war, philosophy and sport in Japanese judo, Journal of Sport History, 20(2), 167-88

Escobar-Molina, R. Courel, J. Franchini, E. Femia, P. Stankovic, N. (20142017), The impact of penalties on subsequent attack effectiveness and combat outcome among high elite judo competitors, International Journal of Performance Analysis in Sport, 14(3), 946-954

Franchini, E. Del Vecchio, F.B. Matsushigue, K.A. Artioli, G.G. (2011), Physiological profiles of elite judo athletes, Sports Medicine, 41(2),147-166

Franchini, E. Artioli, GG. Brito, CJ. (2013a), Judo combat: time-motion analysis and physiology, International Journal of Performance Analysis in Sport 13 (3), 624-641

Franchini, E. Takito, MY. Calmet, M. (2013b), European Judo Championships: impact of the new rule changes on points and penalties, International Journal of Performance Analysis in Sport, 13(2), 474-479

Franchini, E. and Julio, UF. (2015), The Judo World Ranking List and the Performances in the 2012 London Olympics, Asian Journal of Sports Medicine, 6(3), e24045.

IJF - International Judo Federation. (2017), www.ijf.org, accessed on September $10^{\text {th }}$ Ito, K. Hirose, N. Nakamura, M. Maekawa, N. Tamura, M. Hirotsu, N. (2013), The transformation of technical tactical behaviors of hand techniques used in attacking below the belt after the 2010 International Federation rule revision, Archives of Budo, $9,1-6$

Morley, B. and Thomas, D. (2005), An investigation of home advantage and other factors affecting outcomes in English one day cricket matches, Journal of Sports Sciences, 23, 261-268 